\title{
DOE/ER/14190-1
}

\section{Summary Report \\ 1991-2000}

Department of Energy

Basic Energy Sciences

Chemistry Division

Submitted by:

John L. Gland

Department of Chemistry

University of Michigan

Ann Arbor, MI 48109

(734) 764-7354

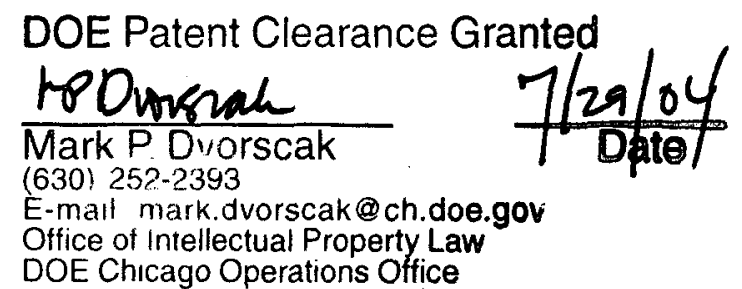




\section{DISCLAIMER}

This report was prepared as an account of work sponsored by an agency of the United States Government. Neither the United States Government nor any agency thereof, nor any of their employees, makes any wartanty, express or implied, or assumes any legal liability or responsibility for the accuracy, completeness, or usefulness of any information, apparatus, product, or process disclosed, or represents that its use would not infringe privately owned rights. Reference herein to any specific commercial product, process, or service by trade name, trademark, manufacturer, or otherwise does not necessarily constitute or imply its endorsement, recommendation, or favoring by the United States Government or any agency thereof. The views and opinions of authors expressed herein do not necessarily state or reflect those of the United States Government or any agency thereof. 


\section{DISCLAIMER}

Portions of this document may be illegible in electronic image products. Images are produced from the best available original document. 


\section{Overview}

This research program, funded by DOE BES Chemical Sciences Division (DE-FG0291ER14190) focused on the development of a fundamental mechanistic understanding for several important classes of hydrogenolysis and oxidation reactions.[1-36] The primary reactions investigated were chosen based on their importance in fuel and chemical production as well as in environmental remediation, and include reactions for hydrodesulfurization (HDS), hydrodenitrogenation (HDN), carbon-carbon hydrogenolysis, and hydrocarbon oxidation. Significant accomplishments during this funding period centered on the two primary thrusts of the proposed work: 1) the development of more powerful measurement schemes and 2) the identification of reaction pathways and dominant intermediates for the key reactions. This summary report will highlight the key advances realized in this research program, with a brief sketch of each area given in the overview, followed by a more complete summary in the body of this report.

New measurement schemes for surface reactions: For the first time, in-situ ultra soft X-ray methods based on fluorescence detection have been developed and demonstrated over an extended range of reaction conditions. Significant measurement advances include

- In-situ measurement of hydrocarbon intermediate stoichiometries and molecular structure

- Direct kinetic determinations under isothermal and isobaric conditions

- Application to increasingly complex surfaces including supported metal particles 
Hydrodenitrogenation (HDN): For aromatic amines, key competition between hydrogenation and dehydrogenation determines structure of surface intermediates, which subsequently controls HDN selectivity and reactivity. Significant HDN advances include

- Open surface structures result in formation of tilted, hydrogenated intermediates, leading to selective, low temperature HDN

- Close-packed surface structures lead to less selective HDN of flat lying, aromatic intermediates

- Hydrogen is DIRECTLY involved in C-N bond breaking process

Hydrodesulfurization (HDS): For aromatic thiols, direct C-S bond breaking by the surface is followed by either hydrogenation or dehydrogenation, which controls the final products formed. Significant HDS advances include

- Open surface structures and moderate reactant coverage result in formation of tilted intermediates, leading to selective, low temperature HDS

- Close-packed surface structures result in less selective HDS

- Hydrogen is NOT DIRECTLY involved in C-S bond breaking

C-C hydrogenolysis: For strained cyclic hydrocarbons, energetic forms of hydrogen initiate hydrogenolysis. Significant C-C hydrogenolysis advances include

- Hydrogen pressures up to 0.1 torr result in limited hydrogenolysis

- Energetic forms of hydrogen initiate hydrogenolysis (subsurface and gas-phase atomic)

- After C-C bond hydrogenolysis, surface structure and hydrogen pressure dictate the final products formed 
Hydrocarbon oxidation: For $\mathrm{C}_{2}$ and $\mathrm{C}_{3}$ hydrocarbon oxidation reactions, a series of oxydehydrogenated intermediates are formed that subsequently undergo skeletal oxidation. Significant hydrocarbon oxidation advances include

- Oxydehydrogenation is the initial reaction step

- Substantial oxygen pressure sensitivity is observed for more complex surfaces (steps, supported particles)

- Acetylene-like intermediates are dominant under catalytic conditions

\section{Introduction}

Catalytic processes involving the hydrogenolysis and oxidation of organic molecules are key to the production of chemicals and fuels, as well as for environmental remediation. This interdisciplinary research program was focused on establishing the dominant reaction pathways and intermediates for hydrogenolysis and oxidation reactions. This new understanding will provide a foundation for innovations in catalytic materials and processes. A series of representative reactions have been characterized on a group of metal surfaces with controlled structure and chemistry. Nickel surfaces with (100) and (111) orientation were chosen to facilitate comparisons between open surfaces with significant hydrogenolysis reactivity, and close-packed surface with smaller hydrogenolysis reactivity. The close-packed Pt(111) surface was chosen to represent a surface with moderate hydrogenolysis reactivity but large oxidation reactivity. The supported platinum thin film surfaces used for oxidation studies were selected as models of supported catalysts. The analogous series of reactants used for hydrogenolysis studies were selected to represent important functional groups for HDN, HDS, and C-C hydrogenolysis. Because of the competitive nature of the HDN and HDS process in initial stages of petroleum refining, direct comparisons between the HDN and HDS mechanisms are especially interesting. 
The organic molecules used for the oxidation studies are representative of chemical feedstocks and hydrocarbon emissions from combustion processes.

\section{Hydrodenitrogenation (HDN)}

During studies of hydrodenitrogenation, two types of molecular mechanisms were observed for $\mathrm{C}-\mathrm{N}$ hydrogenolysis in aromatic molecules on the single crystal $\mathrm{Ni}(100), \mathrm{Ni}(111)$ and $\mathrm{Pt}(111)$ surfaces.[5, 10,11,13-15, 28] On the reactive $\mathrm{Ni}(100)$ surface, selective hydrodenitrogenation of aniline was enhanced by formation of a hydrogenated $\mathrm{C}\left(\mathrm{sp}^{3}\right)-\mathrm{N}$ intermediate adsorbed in a tilted configuration. On the less active (111) surface, aniline adsorbs parallel to the surface with about $20 \%$ undergoing direct hydrogenolysis of a $\mathrm{C}\left(\mathrm{sp}^{2}\right)-\mathrm{N}$ aromatic intermediate, with the remainder being dehydrogenated. Intermediate structure and orientation clearly controls the competition between hydrogenation, dehydrogenation, and hydrogenolysis for aromatic amines. Catalytic hydrodenitrogenation is typically run on molybdenum sulfide catalysts promoted with nickel or cobalt.[37-40] Well-defined nickel surfaces have been used during these fundamental mechanistic studies to model reduced nickel "active sites". Aniline and cyclohexylamine were used as the primary model reactants for these molecular-level studies of hydrodenitrogenation reactions. Direct comparisons between these molecular-mechanistic studies and more qualitative pathway studies on optimized catalysts indicate that similar products and selectivities are observed.[37-39] This comparison suggests that the mechanisms and intermediates observed for these model surfaces play an important role in a broad range of amine hydrodenitrogenation reactions. Hydrogenolysis of aromatic amines can be dominated by direct $\mathrm{C}-\mathrm{N}$ bond activation in aromatic species $\left(\mathrm{C}\left(\mathrm{sp}^{2}\right)-\mathrm{N}\right.$ bond breaking) or by $\mathrm{C}-\mathrm{N}$ bond breaking in a hydrogenated intermediate $\left(\mathrm{C}\left(\mathrm{sp}^{3}\right)-\mathrm{N}\right.$ bond breaking). Both direct $\mathrm{C}-\mathrm{N}$ bond breaking in aromatic species and $\mathrm{C}-\mathrm{N}$ bond breaking in hydrogenated saturated intermediates are 
observed on single crystal $\mathrm{Ni}$ and Pt surfaces. $[5,10,11,13,14]$ These reaction pathways are structure sensitive since $\mathrm{C}\left(\mathrm{sp}^{3}\right)-\mathrm{N}$ bond breaking, in a hydrogenated intermediate, dominates on the $\mathrm{Ni}(100)$ surface; while direct aromatic $\mathrm{C}\left(\mathrm{sp}^{2}\right)-\mathrm{N}$ bond breaking dominates on the $\mathrm{Ni}(111)$ and $\operatorname{Pt}(111)$ surfaces.[5, 10, 13] In both cases, for hydrogenolysis to proceed, substantial hydrogen is required to stabilize the amine hydrogens at reaction temperature. Dehydrogenation of the amine group results in an upright intermediate that cannot be selectively denitrogenated. Hydrogen is DIRECTLY involved in the C-N bond breaking process for both the $\mathrm{C}\left(\mathrm{sp}^{3}\right)-\mathrm{N}$ and $\mathrm{C}\left(\mathrm{sp}^{2}\right)-\mathrm{N}$ mechanisms. Complete hydrodenitrogenation of cyclohexylamine occurs over the $\mathrm{Ni}(100)$ surface via the same intermediate and mechanism but at much lower hydrogen pressures.[10] In both cases, hydrogen-induced $\mathrm{C}-\mathrm{N}$ bond breaking occurs in a tilted cyclohexylamine-like intermediate, which appears to be adsorbed in a (100) hollow site.[10, 13]. Direct hydrodenitrogenation of aromatic $\mathrm{C}\left(\mathrm{sp}^{2}\right)-\mathrm{N}$ intermediates is observed on the $\mathrm{Ni}(111)$ and $\mathrm{Pt}(111)$ surfaces; however, even in 0.02 torr of hydrogen only $20 \%$ of a monolayer of aniline can be hydrodenitrogenated.[5, 10] Spectroscopic studies indicate that direct $\mathrm{C}\left(\mathrm{sp}^{2}\right)-\mathrm{N}$ hydrodenitrogenation proceeds via an aromatic intermediate adsorbed parallel to the surface. Much of this adsorbed aniline is dehydrogenated forming a stable carbonaceous residue even in substantial hydrogen pressures. The parallels between the $C\left(\mathrm{sp}^{2}\right)-\mathrm{N}$ and $\mathrm{C}\left(\mathrm{sp}^{3}\right)-\mathrm{N}$ hydrodenitrogenation mechanisms on the model metal surfaces and on supported catalysts indicates that the understanding developed with these molecular studies is applicable to more complex optimized catalysts systems.

\section{Hydrodesulfurization (HDS)}

During studies of thiol hydrodesulfurization on model Ni and Pt surfaces, we found that C-S bond breaking by the metal surface controls the hydrodesulfurization process. $[2,3,6,9,12$, 
$18,20,21,23,26-28,32,34]$ Hydrogen is not involved in the C-S bond breaking process but plays an important role in controlling the stability of adsorbed species and the final products formed. Nickel promoted molybdenum sulfide catalysts supported on alumina are frequently used for hydrodesulfurization of crude oil, which is a critical part of the refining process.[41-43] Low valent nickel sites play an important role in these catalysts. Well-defined nickel single crystal surfaces have been used during these mechanistic studies to model reduced nickel "active sites". Substituted benzenethiols are important intermediates during hydrodesulfurization of benzothiophenes and dibenzothiophenes, since aromatic thiol bonds are difficult to desulfurize. Based on these observations, benzenethiol and related thiols have been selected as model reactants for these mechanistic studies. During adsorption on Ni surfaces, benzenethiol is adsorbed initially on $\mathrm{Ni}$ surfaces as the thiolate, so thiolate desulfurization is the primary reaction path for this reaction.[6, 18, 23] In-situ soft X-ray absorption studies for hydrogen pressures up to 0.01 torr indicate that hydrogen plays NO DIRECT role in C-S bond breaking. Carbon-sulfur bond breaking by the metal surface is clearly indicated by toluene formation observed during hydrodesulfurization of co adsorbed methanethiol and benzenethiol.[12] Single deuterium incorporation for both the methane and benzene products formed also indicates that adsorbed methyl and phenyl are formed by C-S bond breaking and are then hydrogenated in a later reaction step. Taken together, these results all indicate that hydrogen is not directly involved in $\mathrm{C}-\mathrm{S}$ bond breaking on these $\mathrm{Ni}$ surfaces.

Comparisons between hydrodesulfurization of benzenethiol and cyclohexanethiol on the $\mathrm{Ni}(100)$ and $\mathrm{Ni}(111)$ surfaces reveal that the $\mathrm{C}-\mathrm{S}$ bond in cyclohexanethiol is broken more easily than the C-S bond in benzenethiol.[18, 21, 23, 32] This correlation between C-S bond strength and $\mathrm{C}-\mathrm{S}$ bond breaking supports a homolytic $\mathrm{C}-\mathrm{S}$ bond activation process. For benzenethiol, the orientation of the adsorbed phenylthiolate intermediate also play an important role in controlling 
reactivity. Low benzenethiol coverages favor adsorption geometries almost parallel to surface plane, which strongly favors dehydrogenation. In contrast, tilted aromatic thiolate intermediates formed at intermediate coverages favor low temperature C-S bond breaking. Finally, upright thiolates formed near saturation coverages are much less reactive since the $\mathrm{C}$-S bond does not interact strongly with the surface. Based on this work, the Ni(111) surface favors tilted geometries and favors $\mathrm{C}-\mathrm{S}$ bond breaking. The $\mathrm{Ni}(100)$ surface favors more upright configurations and is less reactive. Hydrodesulfurization and dehydrogenation are more rapid than hydrogenation of aromatic intermediates under the conditions used here so no hydrogenated intermediates (e.g. cyclohexylthiolate) with enhanced reactivities are formed. With substantial increases in hydrogen pressure, hydrogenation before $\mathrm{C}-\mathrm{S}$ bond breaking may further enhance hydrodesulfurization rates.

\section{Hydrogenolysis of C-C Bonds}

Major factors controlling $\mathrm{C}-\mathrm{C}$ bond hydrogenolysis in small cycloalkanes on the $\mathrm{Pt}(111)$ and $\mathrm{Ni}(111)$ surfaces include ring strain in the cycloalkane, the adsorption strengths of the cycloalkane, and the reactivity of the hydrogen species reacting. $[7,16,17,22,24,25,31]$ These $\mathrm{C}-\mathrm{C}$ hydrogenolysis studies are focused on characterizing intermediates and reaction pathways for hydrogenolysis of $\mathrm{C}_{3}$ through $\mathrm{C}_{6}$ cycloalkanes on $\mathrm{Pt}$ and $\mathrm{Ni}$ single crystal metal surfaces. Insitu studies of cyclopropane hydrogenolysis on the $\mathrm{Pt}(111)$ surface in 0.01 torr of hydrogen have clearly established the dominant intermediate species and reaction pathways.[31] During initial stages of reaction, cyclopropane undergoes ring opening to form adsorbed metallocyclobutane. Hydrogenation of the adsorbed metallocycle results in the formation of adsorbed propyl. With increasing temperature propyl is hydrogenated to form the propane product. 
In low pressure experiments, coadsorbed hydrogen does not react even with strained cycloalkanes, since cycloalkane desorption rates are faster than hydrogen addition rates. However, for the strained small cycloalkanes, energetic subsurface hydrogen and gas-phase atomic hydrogen initiates $\mathrm{C}-\mathrm{C}$ bond activation on low index platinum and nickel surfaces. $[7,16$, $19,22,24]$ In contrast, no $\mathrm{C}-\mathrm{C}$ bond breaking is observed for unstrained cyclic hydrocarbons $\left(\mathrm{C}_{5}, \mathrm{C}_{6}\right)$, even though these reactions are thermodynamically feasible with gas-phase atomic hydrogen.[8] This clearly indicates that $\mathrm{C}-\mathrm{C}$ bond breaking is kinetically controlled, even for gas phase atomic hydrogen. The mechanism of $\mathrm{C}-\mathrm{C}$ bond activation in small strained ring systems by energetic forms of hydrogen closely parallels the mechanisms proposed during catalytic studies on $\mathrm{Ni}$ and $\mathrm{Pt}$ at higher pressures and moderate reaction temperatures.[44-46] The initial hydrogen addition process for adsorbed cyclopropane results in the formation of an adsorbed propyl. Adsorbed propyl on the $\mathrm{Ni}(111)$ surfaces is hydrogenated to form propane near $200 \mathrm{~K}$, nearly $80 \mathrm{~K}$ higher than previously observed on the Ni(100) surface.[19, 22] The yield of propane from adsorbed propyl on the $\mathrm{Pt}(111)$ surface is approximately 15 times greater than observed for adsorbed propyl on $\mathrm{Ni}(111)$ indicating that $\mathrm{Pt}$ is a superior hydrogenation catalyst.

\section{Hydrocarbon Oxidation}

Using recently developed soft $\mathrm{X}$-ray methods, oxidation of $\mathrm{C}_{2}, \mathrm{C}_{3}$, and aromatic hydrocarbons have been characterized at the molecular level on the $\operatorname{Pt}(111)$ surface.[29, 30, 33, 35] Using a combination of ultra soft X-ray spectroscopy for characterizing the structure and bonding of reactants and intermediate, temperature programmed fluorescence yield near edge methods to determine the stoichiometry of dominant intermediates, and isothermal and isobaric in-situ kinetic measurements, reaction pathways can be established over a broad range of pressures and temperatures. On the $\mathrm{Pt}(111)$ surface, oxydehydrogenation preceeds $\mathrm{C}-\mathrm{C}$ bond 
oxidation for all of the hydrocarbons studied. Propylene oxidation on the $\operatorname{Pt}(111)$ surface is sequential process with initial oxydehydrogenation forming 1-methyl vinyl. Methylacetylene formed in a second oxydehydrogenation process undergoes rapid skeletal oxidation to form $\mathrm{CO}$ or $\mathrm{CO}_{2} \cdot[29,30]$ Under steady-state catalytic conditions the dominant surface intermediate is methyl acetylene during propylene oxidation. Aromatic oxidation on the $\operatorname{Pt}(111)$ surface proceeds through a series of specific intermediates depending on the substitution of the aromatic ring. $[35,36]$ For instance the first step in benzene oxidation is rehybridization to form a strongly adsorbed di- $\sigma$ species from the $\pi$ bonded species. Oxydehydrogenation of the di- $\sigma$ species results in formation of a tri- $\sigma$ intermediates and further to a quadra- $\sigma$ species. At this point, oxygen addition results in the formation of a phenoxy intermediate which is rapidly oxidized to form $\mathrm{CO}$ and $\mathrm{CO}_{2}$.

\section{Collaborations}

Collaborative research programs were developed with the National Synchrotron Light Source at Brookhaven National Laboratory, $[1,2,5,10,13-15,18,30,31,33,36]$ with the Chemistry Department at Brookhaven National Laboratory, $[26,28]$ with the Chemistry Department at Oak Ridge National Laboratory, $[6,9,12,18,20,23,34]$ and with the Ford Science Laboratories [29, $30,33]$ in the area of hydrocarbon oxidation. Soft X-ray facilities at National Synchrotron Light Source at Brookhaven National Lab were developed as part of the U7A PRT in collaboration with the Chemistry Department at Brookhaven and used for in-situ characterization of reaction kinetics and reaction intermediates. These facilities provide unprecedented sensitivity and flexibility for in-situ characterization of monolayer surface reactions over an extended range of temperatures and pressures. 
1. Gland, J.L., T.S. Rufael, and D.A. Fischer. Ultra-Soft X-ray Absorption Detected by Fluorescence Yield: An In-situ Method for Characterizing Adsorbates and Surface Reactions. in Surface Science of Catalysis. 1992.

2. Rufael, T.S., et al., Hydrogenolysis of Adsorbed Methylthiolate on the Pt(111) Surface. Surface Science, 1992. 278: p. 41-50.

3. Rufael, T.S., et al., Adsorption and Thermal Decomposition of CH3SH on the Pt(111) Surface. Surface Science, 1993. 297: p. 272-285.

4. Huang, S.X., T.S. Rufael, and J.L. Gland, Diimide Formation on the Nickel(100) Surface. Surface Science Letters, 1993. 290: p. L673-L676.

5. Huang, S.X., D.A. Fischer, and J.L. Gland, Correlations between Surface Configurations and Hydrogenolysis: Aniline on the Pt(111) Surface A12. Journal of Vacuum Science and Technology, 1994: p. 2164-2169.

6. Rufael, T.S., et al., Adsorption and Reactions of Benzenethiol on the Ni(111) Surface. Journal of Physical Chemistry, 1994. 98: p. 13022-13027.

7. Son, K.-A. and J.L. Gland, Carbon-Carbon Bond Activation in Cyclopropane by Energetic Forms of Hydrogen on the Ni(100) Surface. Journal of the American Chemical Society, 1995. 117: p. 5415-5416.

8. Son, K.-A., M. Mavrikakis, and J.L. Gland, Low Temperature Hydrogenation of Cyclohexene by Energetic Forms of Hydrogen on the Ni(100) Surface. Journal of Physical Chemistry, 1995. 99: p. 6270-6272.

9. Rufael, T.S., et al., Methylthiolate on Ni(111): Multiple Adsorption Sites and Mechanistic Implications. Journal of Physical Chemistry, 1995. 99: p. 11472-11480.

10. Huang, S.X., D.A. Fischer, and J.L. Gland, Aniline Hydrogenolysis on Nickel: Effects of Surface Hydrogen and Surface Structure. Catalysis Letters, 1995. 34: p. 365-374.

11. Huang, S.X. and J.L. Gland, Cyclohexylamine Adsorption and Hydrogenolysis on the Ni(100) Surface. Journal of Physical Chemistry, 1996. 100: p. 2206-2212.

12. Kane, S.M., D.R. Huntley, and J.L. Gland, Toluene Formation from Coadsorbed Methanethiol and Benzenethiol on the Ni(111) Surface. Journal of the American Chemical Society, 1996. 118: p. 3781-3782.

13. Huang, S.X., D.A. Fischer, and J.L. Gland, Aniline Adsorption, Hydrogenation, Hydrogenolysis on the Ni(100) Surface. Journal of Physical Chemistry, 1996. 100: p. 10223-10234.

14. Huang, S.X., D.A. Fischer, and J.L. Gland. Hydrogenation and Hydrogenolysis of Aniline on the Nickel Single Crystal Surfaces: Mechanistic Implications of HDN Reactions. in Hydrotreating Technology for Pollution Control,. 1996: Marcel-Dekker, New York.

15. Huang, S.X., D.A. Fischer, and J.L. Gland, In Situ Studies of Cyclohexylamine Dehydrogenation and Hydrogenation on the Ni(111) Surface. Journal of Physical Chemistry, 1996. 100: p. 13629-13635.

16. Son, K.-A. and J.L. Gland, Gas Phase Atomic Hydrogen Induced Carbon-Carbon Bond Activation in Cyclopropane on the Ni(100) Surface. Journal of the American Chemical Society, 1996. 118: p. 10505-10514.

17. Son, K.-A. and J.L. Gland, Gas Phase Atomic Hydrogen-Induced Hydrogenation of Cyclohexene on the Ni(100) Surface. Journal of Physical Chemistry B, 1997. 101: p. 3540-3546.

18. Kane, S.M., et al., The Role of Hydrogen in Benzene Formation from Benzenethiol on the Ni(11) Surface. Journal of Physical Chemistry B, 1997. 101: p. 8486-8491. 
19. Capitano, A.T. and J.L. Gland, Gas Phase Atomic Hydrogen Induced Carbon-Carbon Bond Activation in Cyclopropane on the Pt(111) Surface. Journal of Physical Chemistry B, 1998. 102: p. 2562-2568.

20. Rufael, T.S., et al., Adsorption and Reaction of Dimethyl Disulfide on the Ni(111) Surface. Journal of Physical Chemistry B, 1998. 102: p. 3431-3440.

21. Kane, S.M. and J.L. Gland, Cyclohexanethiol Adsorption and Reaction on the Ni(111) Surface. Journal of Physical Chemistry B, 1998. 102: p. 5322-5328.

22. Capitano, A.T. and J.L. Gland, Carbon-Carbon Bond Activation in Cyclopropane by Subsurface Hydrogen on the Ni(11I) Surface. Langmuir, 1998. 14: p. 1345-1347.

23. Kane, S.M., D.R. Huntley, and J.L. Gland, Benzenethiol Reaction on the Clean and Hydrogen Pretreated Ni(100) Surface. Journal of Physical Chemistry B, 1998. 102: p. 10216-10222.

24. Capitano, A.T., K.-A. Son, and J.L. Gland, C-C Bond Activation in Cyclopropane Induced by Gas Phase Atomic Hydrogen on the Ni(111) Surface. Journal of Physical Chemistry B, 1999. 103: p. 2223-2227.

25. Capitano, A.T., A.M. Gabelnick, and J.L. Gland, Gas Phase Atomic Hydrogen Reacting with Molecular and Atomic Oxygen to Form Water on the Pt(111) Surface. Surface Science Letters, 1999. 419: p. 104-113.

26. Rodriguez, J.A., et al., Adsorption of Thiophene on Surfaces of Clean and Ni-Promoted Molybdenum Sulfide. Surface Science, 1999. 429: p. L462-L468.

27. Capitano, A.T. and J.L. Gland, Desulfurization of the Ni(100) surface Using Gas-phase Atomic Hydrogen Radicals. Journal of Physical Chemistry B, 1999. 103: p. 6573-6578.

28. Rodriguez, J.A., et al., Chemistry of Thiophene, Pyridine, and Cyclohexylamine on $\mathrm{Ni} / \mathrm{MoSx}$ and Ni/S/Mo(110) Surfaces: Role of Nickel in Hydrodesulfurization and Hydrodenitrogenation Processes on Surfaces of Clean and Ni-Promoted Molybdenum Sulfide. Journal of Physical Chemistry B, 1999. 103: p. 8310-8318.

29. Gabelnick, A.M. and J.L. Gland, Propylene Deep Oxidation on the Pt (111) Surface: Temperature Programmed Studies over Extended Coverage Ranges. Surface Science, 1999. 440: p. 340-350.

30. Gabelnick, A.M., et al., Propylene Oxidation Mechanisms and Intermediates Using Insitu Soft X-ray Fluorescence Methods on the Pt (111) Surface. Journal of the American Chemical Society, 2000. 122: p. 143-149.

31. Capitano, A.T., A.M. Gabelnick, and J.L. Gland, Catalytic Cyclopropane Hydrogenation on Pt(111) Using In-Situ Soft X-ray Methods. Journal of Physical Chemistry B, 2000.

104: p. 3337-3342.

32. Kane, S.M. and J.L. Gland, Cyclohexanethiol Adsorption and Reactions on the Ni(100). Surface Science, 2000. 468: p. 101-108.

33. Gabelnick, A.M., et al., Molecular Mechanisms of Propyne Oxidation on the Pt(111) Surface: In-situ Soft X-ray Studies in Pressures of Oxygen. Journal of Physical Chemistry B, 2001. 105: p. 7748-7754.

34. Kane, S.M., D.R. Huntley, and J.L. Gland, Toluene Formation from Coadsorbed Methanethiol and Benzenethiol on Nickel Surfaces. Journal of Physical Chemistry B, 2001. 105: p. 9548-9556.

35. Marsh, A.L. and J.L. Gland, Mechanisms of Deep Benzene Oxidation on the Pt(111) Surface Using Temperature Programmed Reaction Methods. Surface Science, 2003. 536: p. 145-154. 
36. Marsh, A.L., et al., Benzene Intermediates and Mechanisms during Catalytic Oxidation on the Pt(111) Surface Using In-Situ Soft X-ray Methods. Journal of Physical Chemistry B, 2003. 107: p. 12472-12479.

37. Shabtai, J., et al., Catalytic Functionalities of Supported Sulfides V. C-N Bond Hydrogenolysis Selectivity as a Function of Promoter Type. Journal of Catalysis, 1988. 113: p. 206-219.

38. Jian, M. and R. Prins, Determination of the Nature of Distinct Catalytic Sites in Hydrodenitrogenation by Competitive Adsorption. Catalysis Letters, 1998. 50: p. 9-13.

39. Jian, M. and R. Prins, Kinetics of the Hydrodenitrogenation of Decahydroquinoline over NiMo(P)/Al2O3 Catalysts. Industrial Engineering Chemical Research, 1998. 37: p. 834840.

40. Ho, T.C., Hydrodenitrogenation Catalysis. Catalysis Review Science and Engineering, 1988. 30: p. 117-160.

41. Satterfield, C.N., Heterogeneous Catalysis in Practice. 1980: McGraw-Hill Book Company.

42. Prins, R., H.J. DeBeer, and G.A. Somorjai, Structure and Function of the Catalyst and the Promoter in Co-Mo Hydrodesulfurization Catalysts. Catalysis Review Science and Technology, 1989. 31: p. 1-41.

43. Eijsbouts, S., On the Flexibility of the Active Phase in Hydrotreating Catalysts. Applied Catalysis A: General, 1997. 158: p. 53-92.

44. Sinfelt, J.H., Specificity in Catalytic Hydrogenolysis by Metals, in Advances in Catalysis. 1973. p. 91-119.

45. Goodman, D.W., Structure/Reactivity Relationships for Alkane Dissociation and Hydrogenolysis Using Single Crystal Kinetics. Catalysis Today, 1992. 12: p. 189-199.

46. Somorjai, G.A., Introduction to Surface Chemistry and Catalysis. 1994: John Wiley \& Sons Inc. 